\title{
Editorial: The new editorial team
}

I am pleased to inform readers that a very strong editorial team has been appointed to take Ageing \& Society forward. Professor Christina Victor of Brunel University in West London will be the new Editor (the handover was on Ist October 2010). I have greatly admired Christina's empirical research (we have published excellent papers from her on loneliness) and the energy she has put into editing numerous monographs, collections and the British Society of Gerontology's Generations Review. Her work on the health of older people is perhaps most widely known. Dr Jim Ogg will be Deputy Editor of the journal: he has been an Associate Editor for nearly two years and has stimulated submissions of papers from France and other European countries. Two additional Associate Editors have been appointed: Glenda Cook of the Centre for Collaborative Gerontology at the University of Northumbria, and Sally Keeling of the Department of Medicine, University of Otago, Christchurch, New Zealand. It is exciting that the journal now has a second Associate Editor based outside the UK. The new team undoubtedly has the skills, range of interests and judgement to accelerate the progress of the journal and to take it in new directions.

I will indulge in a brief reflection about my own impending life transition, for I have been closely associated with Ageing \& Society through much of my career. I was a member of the Editorial Board before I became the Review Editor in 1987. Over the next Io years, I worked most agreeably with the successive editors, Malcolm Johnson, Peter Coleman and Bill Bytheway. After four years' sabbatical, I was appointed as Editor on that momentous day in 200I, 9/Ir. For the train journey home I bought an early edition of the London Evening Standard. It had a front-page photograph of the plane hitting the first fated tower, but the paper was unsure if it was accidental or a terrorist outrage. There was a lot to take in that evening.

To me, the distinctive qualities and contribution of social gerontology research, scholarship and teaching are its inquisitiveness about the experience of old age and its empathy with older people. Raising our understanding of later life and older people does have 'applied' intents, but they are broader and less immediate and instrumental than the goals of our clinical and professional academic colleagues, and attract less scientific prestige than fundamental biology. Social gerontology's ambitions include reducing the marginalisation of older people, exposing stereotyping and belittling, reducing middle-aged and younger people's ignorance and 


\section{I292 Editorial}

thoughtlessness about old age, and combating the widely felt fear or abhorrence of personal ageing. Social gerontology has a hard time persuading our biomedical colleagues that its distinctive aims are important complements to understanding pathology and developing therapies that deliver more immediate returns to health and wellbeing. We have an even harder time persuading macroeconomists and some high-level policy makers that rising longevity and the growing number of older people is a success and should be celebrated, not least for the new societal and family resources that a larger population of healthy older people brings.

In previous editorials, I have welcomed the expanding range and rising quality of research and writing in social gerontology. Over the last two years, particularly, I have been struck by the evidence that authors with social gerontology motivations are establishing themselves in the academic and professional structures of many countries far beyond the subject's established bases. In many countries, those with social gerontological imagination and ambitions are countering the initial negative responses to demographic ageing and rising longevity. I am delighted to see the 'social gerontology enterprise' prosper and grow, and proud of the contribution that Ageing \& Society has made to the promotion and dissemination of its understanding. May the journal go from strength to strength.

\section{TONY WARNES}

